\title{
TITLE OF WRITE-UP
}

Hypertension at late preterm gestation: deliver immediately or watch and wait?

\section{REVIEWED BY}

Name, Title: Elaine M Boyle MBChB, PhD

Institution: University of Leicester

Email: eb124@le.ac.uk

\section{CORRESPONDING AUTHOR}

Name: Elaine M Boyle

Email: eb124@le.ac.uk

Telephone: 01162525447

\section{TITLE OF WRITE-UP}

Hypertension at late preterm gestation: deliver immediately or watch and wait?

\section{MANUSCRIPT CITATION}

Broekhuijsen K, van Baaren G-J, van Pampus MG, Ganzevoort W, Sikkema JM, Woiski $M D$, Broekhuijsen K, van Baaren G-J, van Pampus MG, Ganzevoort W, Sikkema JM, Woiski MD, Oudjik MA, Bloemenkamp KW, Scheepers HC, Bremer HA, Rjinders RJ, van Loon AJ, Perguin DA, Sproken JM, Papatsonis DN, van Huizen ME, Vredevoogd CB, Brons JT, Kaplan M, van Kaam AH, Groen H, Porath MM, van den Berg PP, Mol BW, Franssen MT, Langenveld J, HYPITAT-II study group. Immediate delivery versus expectant monitoring for hypertensive disorders of pregnancy between 34 and 37 weeks of gestation (HYPITAT-II): an open-label, randomized controlled trial. Lancet 2015. PMID: 25817374

\section{REVIEWED BY}

Name, Title: Elaine M Boyle MBChB, PhD

Institution: University of Leicester

Email: eb124@le.ac.uk

TYPE OF INVESTIGATION

Prevention 


\section{QUESTION}

In pregnant women with hypertensive disorders between $34+0$ and $36+6$ weeks of gestation, does expectant management (aiming to prolong pregnancy until 37 weeks of gestation) compared to immediate delivery, reduce risks of adverse maternal and neonatal outcomes?

\section{METHODS}

- Design: Randomized controlled trial

- Allocation: Randomization was via a web-based system using block randomization with variable (range 2-4) block size and was stratified by center. Allocation was 1:1.

- Blinding: Participants, clinicians and outcome assessors were not blinded to the treatment allocation.

- Follow-up period: Maternal data were collected until final hospital discharge and at 6 weeks following delivery. Neonatal outcome data were collected until final discharge of the neonate from hospital.

- Setting: 51 maternity centers, of which seven were academic centers and 44 were non-academic hospitals in the Netherlands, between March 2009 and February 2013.

- Patients: Pregnant women between $34+0$ and $36+6$ weeks of gestation (by ultrasound scan) were eligible to participate in the trial if they had a non-severe hypertensive disorder: gestational hypertension, pre-eclampsia, deteriorating preexisting hypertension or superimposed pre-eclampsia. Exclusion criteria were: severe hypertension, severe proteinuria, oliguria, HELLP syndrome, pulmonary oedema or cyanosis; non-reassuring fetal heart trace or reversed end diastolic flow; maternal or fetal comorbidity that would have affected management or treatment effect; ruptured membranes or other condition the attending clinician judged that prolongation of pregnancy was contraindicated. Multiple births were included.

- Intervention: Women were assigned to either immediate delivery or expectant management, with delivery planned at 37 weeks of gestation. In those assigned to immediate delivery, labour was induced. Women in whom the attending clinician considered that either induction of labour or vaginal delivery was contraindicated were delivered by caesarean section. Those who were assigned to expectant management were monitored either in outpatient clinics or as inpatients, depending on their condition. Monitoring was performed according to the local guidance, but incorporated, as a minimum, regular blood pressure monitoring, twice weekly screening for proteinuria and fetal heart rate monitoring and assessment of fetal movements. Women for whom prolongation of pregnancy was contraindicated were delivered before 37 weeks of gestation. Anti-hypertensive treatment was given according to national guidelines.

- Outcomes:

1. Maternal

o Primary outcome: The primary maternal outcome was a composite of 
adverse outcomes, defined as one or more of the following:

- Thromboembolism

- Pulmonary edema

- HELLP syndrome

- Eclampsia

- Placental abruption

- Maternal death

- Secondary outcomes: Secondary maternal outcomes were instrumental delivery and caesarian section.

\section{Neonatal}

- Primary outcomes: The primary neonatal outcomes was respiratory distress syndrome (RDS), defined as the need for supplemental oxygen for $>24$ hours combined with typical radiological findings

- Secondary outcomes: Secondary neonatal outcomes were:

- Apgar score of $<7$ at 5 minutes

- Umbilical artery $\mathrm{pH}<7.05$

- Neonatal unit admission

- Death before discharge

- Suspected or confirmed neonatal infection

- Hypoglycemia requiring intervention with glucose infusion

- Transient tachypnoea of the newborn

- Meconium aspiration syndrome

- Pneumothorax or pneumomediastinum

- Necrotizing enterocolitis

- Intraventicular haemorrhage

- Periventricular leukomalacia

- Convulsions

- Analysis and Sample Size:

Sample size was based on results from the first HYPITAT study ${ }^{1}$ which, using similar methodology, showed a $3.4 \%$ risk of composite adverse maternal outcome in the expectant management group. Assuming a slightly higher risk in pregnancies affected at earlier gestations, it was hypothesized that, in the HYPITAT II study, immediate delivery would reduce adverse maternal outcomes from $5 \%$ in the expectant management group to $1 \%$ in the immediate delivery group, allowing for $10 \%$ deviation from protocol. They calculated that 340 women per group would allow detection of this difference using a two-sided test with $80 \%$ power at the $5 \%$ significance level. With respect to the primary neonatal outcome, this sample size would also allow assessment of the rates of RDS, which they expected to be $8 \%$ in neonates born to mothers in the immediate delivery group and 3\% in the expectant management group. Statistical analyses were by intention to treat. For multiple births, neonatal outcomes were considered to be present if at least one neonate was affected.

- Patient follow-up: 897 eligible women were invited to participate in the study. Of these, 704 were randomized. Primary outcome data were analyzed for 352/353 
women allocated to immediate delivery and for all 351 women allocated to expectant management.

\section{MAIN RESULTS}

\begin{tabular}{|c|c|c|c|c|}
\hline & $\begin{array}{l}\text { Immediate } \\
\text { delivery } \\
(n=352)\end{array}$ & $\begin{array}{c}\text { Expectant } \\
\text { management } \\
\quad(n=351)\end{array}$ & $\begin{array}{l}\text { Relative risk } \\
(95 \% \mathrm{CI})\end{array}$ & $\begin{array}{l}\text { Absolute } \\
\text { risk } \\
\text { difference } \\
(95 \% \mathrm{Cl})\end{array}$ \\
\hline \multicolumn{5}{|l|}{ Maternal Outcomes } \\
\hline \multicolumn{5}{|l|}{ Primary outcome } \\
\hline $\begin{array}{l}\text { Composite adverse } \\
\text { outcomes, n (\%) }\end{array}$ & $4(1)$ & $11(3)$ & $\begin{array}{c}0.36 \\
(0.12 \text { to } \\
1.11) \\
\end{array}$ & $\begin{array}{c}2.0 \\
(-0.2 \text { to } 4.5)\end{array}$ \\
\hline \multicolumn{5}{|l|}{ Secondary outcomes } \\
\hline $\begin{array}{l}\text { Vaginal instrumental } \\
\text { delivery, } \mathrm{n}(\%)\end{array}$ & $32(9)$ & $34(10)$ & $\begin{array}{c}0.94 \\
(0.59 \text { to } \\
1.49) \\
\end{array}$ & $\begin{array}{c}0.6 \\
(-3.8 \text { to } 5.0)\end{array}$ \\
\hline $\begin{array}{l}\text { Caesarean section, } \mathrm{n} \\
(\%)\end{array}$ & $107(30)$ & $114(32)$ & $\begin{array}{c}0.94 \\
(0.75 \text { to } \\
1.16)\end{array}$ & $\begin{array}{c}2.1 \\
(-4.8 \text { to } 8.9)\end{array}$ \\
\hline \multicolumn{5}{|l|}{ Neonatal outcomes } \\
\hline \multicolumn{5}{|l|}{ Primary outcome } \\
\hline $\begin{array}{l}\text { Respiratory distress } \\
\text { syndrome, } \mathrm{n}(\%)\end{array}$ & $20(5.7)$ & $6(1.7)$ & $\begin{array}{c}3.3 \\
(1.4 \text { to } 8.2)\end{array}$ & $\begin{array}{c}4.0 \\
(1.2 \text { to } 7.1)\end{array}$ \\
\hline \multicolumn{5}{|l|}{ Secondary outcomes } \\
\hline NICU admission & $26(7.4)$ & $13 / 350(3.7)$ & $\begin{array}{c}2.0 \\
(1.0 \text { to } 3.8) \\
\end{array}$ & $\begin{array}{c}3.7 \\
(0.3 \text { to } 7.2) \\
\end{array}$ \\
\hline $\begin{array}{l}\text { Transient tachypnea of } \\
\text { the newborn }\end{array}$ & $20 / 349(5.7)$ & $6 / 348(1.7)$ & $\begin{array}{c}3.3 \\
(1.4 \text { to } 8.2) \\
\end{array}$ & $\begin{array}{c}4.0 \\
(1.2 \text { to } 7.1) \\
\end{array}$ \\
\hline $\begin{array}{l}\text { Any neonatal } \\
\text { morbidity }\end{array}$ & $\begin{array}{c}131 / 267 \\
(49.1)\end{array}$ & $\begin{array}{l}89 / 245 \\
(36.3 f)\end{array}$ & $\begin{array}{c}1.4 \\
(1.1 \text { to } 1.7)\end{array}$ & $\begin{array}{c}12.7 \\
(4.2 \text { to } 21.0)\end{array}$ \\
\hline
\end{tabular}

$\S$ Includes RDS; Classified as normal if: umbilical artery $\mathrm{pH}$ was missing and other components were normal; if $\mathrm{PVL} / \mathrm{IHH}$ were missing and cerebral imaging had not taken place

In the expectant monitoring group, 36\% of women were delivered before 37 weeks of gestation because of concerns about maternal or fetal wellbeing. HELLP syndrome, eclampsia and placental abruption were each more common in the expectantly managed women, but numbers of all adverse outcomes were small and differences did not reach statistical significance. There were no maternal deaths in either group. The primary neonatal outcome occurred was significantly increased in the immediate delivery group compared the expectant monitoring group, yielding a number needed to harm of 25. Admission to a neonatal unit, transient tachypnea of the newborn were also more common in the immediate delivery group, with numbers needed to harm of 27 and 25 respectively. Post-hoc analysis showed a higher risk of overall neonatal 
morbidity in the immediate delivery group.

\section{CONCLUSION}

The authors conclude that, in women with non-severe hypertensive disorders at $34+0$ to $36+6$ weeks of gestation, whilst fewer adverse maternal outcomes were seen with immediate delivery than with expectant management, the risk for the neonate of developing respiratory distress syndrome was significantly increased. In view of the increased risk to the infant, they concluded that routine immediate delivery is not justified and expectant monitoring is reasonable until the woman's clinical condition deteriorates

\section{COMMENTARY, limited to 500 words}

Hypertensive disorders are common complications of pregnancy with associated maternal and infant risks. In severe hypertensive disorders beyond 34 weeks gestation, risks of prolonging pregnancy outweigh those of early delivery. For pregnancies complicated by severe hypertension before 34 weeks, risks of prematurity may warrant cautious monitoring and attempts to delay delivery. The first HYPITAT trial $^{1}$ (2009), considered non-severe hypertensive disorders of pregnancy and demonstrated that immediate delivery led to reduction in maternal morbidities, without substantially increasing risks to the baby.

Recommendations for women with non-severe hypertensive disorders at late preterm gestation (34 to 36 weeks) are much less clear; opinion has been divided regarding optimal timing of delivery². The American College of Obstetrics and Gynecology recommends expectant management for women at late preterm gestations ${ }^{3}$. In the United Kingdom the National Institute for Health and Care Excellence recommends that women with mild or moderate pre-eclampsia at late preterm gestations should be offered delivery, "depending on maternal and fetal condition, risk factors and availability of neonatal intensive care", whereas women with gestational hypertension should not be offered delivery before 37 weeks ${ }^{4}$. The World Health Organisation (WHO), in recommendations for prevention and treatment of pre-eclampsia and eclampsia, suggests that expectant management may be appropriate in some women at 34 to 36 weeks with severe hypertension, providing that monitoring is available. It acknowledges that the quality of evidence on which their guidance is based is low.

This randomized trial aims to answer this question and provide some clarification. Results for the composite maternal outcome suggest that immediate delivery leads to decreased maternal morbidities; however numbers of women with the primary outcome were small and, for each individual component of the composite outcome, very small. The finding of increased rates of RDS in neonates whose mothers were delivered immediately was more convincing and overall, the results are supportive of expectant management. This is in contrast to evidence for hypertensive disorders at 
term. The risks of stillbirth associated with expectant management must not be underestimated; further evidence is probably needed before we can be fully confident that this is the optimal approach.

The short-term neonatal outcome, RDS, was chosen, which is known to be relatively common in late preterm compared with term born infants 5 . However, mounting evidence suggests these infants are also at risk of long-term problems, with associations observed between pre-eclampsia and adverse neonatal outcomes and neurodevelopmental outcomes at two years of age 7,8 . Since hypertensive disorders of pregnancy are common indications for delivery at late preterm gestations, the planned follow-up of this cohort at two and five years will be important to determine whether any long-term effects exist. Further work is also needed to elucidate whether particular antenatal diagnoses place women and their babies at greater risk than hypertension per se, but large numbers will be required to study individual diagnoses.

Until further evidence is available, it seems reasonable to employ cautious expectant management of women with non-severe hypertension at late preterm gestation to minimize adverse neonatal outcomes without increasing risks of adverse maternal outcomes.

\section{FUNDING}

None

\section{CONFLICTS OF INTEREST}

\section{None}

\section{REFERENCES, only for the Commentary section and limited to 9}

1. Koopmans CM, Bijlenga D, Groen $\mathrm{H}$, et al. Induction of labour versus expectant monitoring for gestational hypertension or mild pre-eclampsia after 36 weeks' gestation (HYPITAT): a multicentre, open-label randomised controlled trial. Lancet 2009;374:979-88.

2. Gillon TE, Pels A, von Dadelszen P, MacDonell K, Magee LA. Hypertensive disorders of pregnancy: a systematic review of international clinical practice guidelines. PloS one 2014;9:e113715.

3. American College of Obstetricians and Gynecologists. Hypertension in pregnancy. Report of the American College of Obstetricians and Gynecologists' Task Force on Hypertension in Pregnancy. Obstetrics and gynecology 2013;122:1122-31.

4. National Institute for Health and Clinical Excellence. Hypertension in pregnancy: the management of hypertensive disorders during pregnancy. National Collaborating Centre for Women's and Children's Health.; 2010.

5. Boyle EM, Johnson S, Manktelow B, et al. Neonatal outcomes and delivery of care for infants born late preterm or moderately preterm: a prospective population- 
based study. Archives of disease in childhood Fetal and neonatal edition 2015. doi 10.1136/archdischild-2014-307347

6. Natile M, Ventura ML, Colombo M, et al. Short-term respiratory outcomes in late preterm infants. Italian journal of pediatrics 2014;40:52.

7. Johnson S, Evans TA, Draper ES, et al. Neurodevelopmental outcomes following late and moderate prematurity: a population-based cohort study. Archives of disease in childhood Fetal and neonatal edition 2015. doi 10.1136/archdischild-2014307684

8. Masoura S, Kalogiannidis I, Margioula-Siarkou C, et al. Neonatal outcomes of late preterm deliveries with pre-eclampsia. Minerva ginecologica 2012;64:109-15. 